Research Article

\title{
Flexural Behavior of Unbonded Prestressed Concrete Bridge Girders
}

\author{
Chenhao Tang $\mathbb{D}^{1}{ }^{1}$ Gang Zhang $\mathbb{D}^{1},{ }^{1}$ Chaojie Song, ${ }^{1}$ Xuyang Li, ${ }^{1}$ and Yonggang Hou ${ }^{2}$ \\ ${ }^{1}$ School of Highway, Chang'an University, Xi'an, Shaanxi 710064, China \\ ${ }^{2}$ Ningxia Highway Survey and Design Institute Co Ltd, Yinchuan, Ningxia 750000, China \\ Correspondence should be addressed to Gang Zhang; zhangg_2004@126.com
}

Received 31 December 2020; Revised 13 March 2021; Accepted 17 March 2021; Published 31 March 2021

Academic Editor: Zhigang Zhang

Copyright ( $(2021$ Chenhao Tang et al. This is an open access article distributed under the Creative Commons Attribution License, which permits unrestricted use, distribution, and reproduction in any medium, provided the original work is properly cited.

This paper presents an experimental and numerical investigation on the flexural behavior of unbonded prestressed concrete (PC) $\mathrm{T}$ bridge girders. Three unbonded PC T bridge girders with different prestress degrees spanning $3 \mathrm{~m}$ were selected to perform four-point bending tests and then determine the flexural performance. Flexural capacity, crack development and failure mode, load-deflection curves, strain in longitudinal rebars, and stress in prestressing strands of unbonded PC T bridge girders are experimentally analyzed. Subsequently, three-dimensional finite element (FE) models are built and validated by experiments to investigate the effect of different design parameters on flexural behavior of bridge girders. Results generated from experiment and numerical studies show that the flexural destruction behavior in unbonded PC T bridge girders experiences elastic, elastic-plastic, and ductility stages, similar to that of PC T bridge girders. The prestress degree and load location have significant influence on the destruction process in unbonded PC T bridge girders. A lower effective prestress degree can reduce the distribution range in cracks and also increase the width of cracks. Stress in prestressing strands under anchor increases rapidly after concrete presents obvious cracks, and the fracture area within prestressing strands increases with the elevation of prestress degree. The aim of this study is to provide a reference for the design and practical application of unbonded PC T bridge girders.

\section{Introduction}

Unbonded prestressed concrete (PC) bridge girders belong to post-tensioned concrete girders with prominent characteristic applying prestress mainly dependent on anchors and also little friction between prestressing strands and concrete. Unbonded PC bridge girders present many advantages, namely, convenience to stretch, lower cross-sectional height, reducing friction loss of prestress, preventing rust of strands after concrete crack, and avoiding the quality problem caused by grouting. Therefore, unbonded PC bridge girders have a wide application prospect and value during the construction of medium- and small-span bridges and the reinforcement of old bridges.

In the past few decades, some experiment and numerical studies have been performed to investigate flexural behavior in unbounded PC beams. Peng et al. [1] proposed calculation methods on flexural capacity of unbonded PC concrete members together with ultimate stress of unbonded prestressing strands. Moreira et al. [2] undertook a finite element (FE) simulation of unbonded PC beams and then developed a convergence method of Newton-Raphson scheme. Páez and Sensale [3] presented an analysis approach on over time of unbonded PC beams and then improved the formulas of calculating loss in prestress. Lazzari et al. [4] put forward suggestions of design procedures in bonded and unbonded PC flexural members. Li et al. [5] studied bending performance of unbonded PC beams with basalt fiber and reclaimed aggregate by experiments and established the formulas of calculating the flexural capacity and maximum crack width in unbonded PC beams. Kim et al. [6] evaluated flexural performance of post-tensioned PC beams with $2400 \mathrm{MPa}$ of high-strength strands dependent on eleven test specimens, and results showed that design criteria provided from ACI 318 [7] and AASHTO [8] underestimated increase of stress in high-strength strands. Bonopera et al. [9] 
performed an experiment on PC I-shaped beam using a parabolic unbounded tendon and then confirmed the fundamental frequency was not adapt to predict prestress loss. Because the strain of unbonded prestressing strands is uniformly distributed along the girder length, unbonded prestressing strands often fail to completely reach the ultimate strength when the girder is destroyed. And the code standards of ACI, JGJ, and DIN emphasized the necessity of calculating the flexural strength in unbonded PC structures. However, most of the studies focused on rectangular- or box-section beams, and less information on $\mathrm{T}$ girders $[10,11]$. Further, limited studies have focused on flexural behavior, including flexural capacity, failure mode, loaddeflection, and stress in prestressing strands of unbounded PC $\mathrm{T}$ bridge girders with different prestress degrees.

This study aims to investigate the flexural behavior of unbonded PC T bridge girders with different prestress degree counting on experimental and numerical studies. First, the ultimate flexural capacity and failure mechanism of unbonded PC T bridge girders are investigated through the load-to-destruction test. Second, FE models used to verify experiments are applied to analyze factors affecting the flexural capacity of unbounded PC T bridge girders. Finally, some recommendations for the design and practical application of unbonded PC T bridge girders are provided to engineers and designers.

\section{Experimental Program}

To investigate the flexural behavior of unbonded PC T bridge girders, three unbonded PC T girders, herein referred to as SP-A, SP-B and SP-C, were prepared and tested.

2.1. Test Specimens. According to the principle of equivalent stiffness, three scaled experimental specimens are designed based on a selected T bridge girder with span of $20 \mathrm{~m}$. Traverse and longitudinal sections of specimens are shown in Figure 1. The total length and clear span of specimens are $3300 \mathrm{~mm}$ and $3000 \mathrm{~mm}$, respectively. The height and width of cross-section are all $600 \mathrm{~mm}$. The height and thickness of the web are $420 \mathrm{~mm}$ and $240 \mathrm{~mm}$, respectively. The design of strength in concrete is $40 \mathrm{MPa}$. The prestressing strands are made of $3 \times 7 \mathrm{~A}^{\mathrm{s}} 15.2$ using tensile strength of $1860 \mathrm{MPa}$. The tensile strength of rebars and stirrup is $400 \mathrm{MPa}$ and $300 \mathrm{MPa}$, respectively. The prestressing strands with different prestress degree $(25.6 \%, 10.3 \%)$ are tensioned after 28 days of concrete casting. Herein, the prestress degree can be defined as the ratio of tensile stress to design stress. The fabrication procedure is shown in Figure 2.

2.2. Material Properties. The material properties in concrete, rebars, and prestressing strands were examined using universal testing machines, as shown in Table 1.

2.3. Test Equipment and Procedure. The four-point bending test was carried out to investigate the flexural behavior of unbonded PC T bridge girders. Specimens were simply supported at both ends, and pressure testing machine with measurement range of $2000 \mathrm{kN}$ was selected to provide the test load. The load was implemented through a load distributing beam supported at two load-acting points on the test girders. Herein, the distance between the load-acting points in SP-A, SP-B, and SP-C was $500 \mathrm{~mm}, 750 \mathrm{~mm}$, and $500 \mathrm{~mm}$, respectively. A pressure sensor was placed between pressure testing machine and load distributing beam to record the enforced loading. Displacement meters were installed at the mid-span and quarter-span to record the deflection, as shown in Figure 3. The design testing parameters in SP-A, SP-B, and SP-C are summarized in Table 2.

The loading process was divided into two stages: preloading and formal loading. Preloading of $50 \mathrm{kN}$ with interval of $30 \mathrm{~min}$ was implemented to eliminate the gap between the servo loading system and the test girders. At the formal loading stage, the load increased by a level of $50 \mathrm{kN}$ each time until the mid-span deflection reached $50 \mathrm{~mm}$; thereafter, the load step size became smaller increased by a level of $20 \mathrm{kN}$ each time until structure was thrown into failure. At each level of loading, the deflection of test girders and the strain in rebars were automatically recorded dependent on displacement meter and strain gauges, respectively. Stress in prestressing strands was obtained by recording the deformation of pressure sensor. The appearance and propagation of concrete cracking and the development in crack width, detailedly observed and recorded, were utilized to analyze the development law of crack in unbonded PC T bridge girder under different prestress degree and load conditions.

\section{Experimental Results}

Flexural capacity, crack development, failure mode, loaddeflection curves, strain in longitudinal rebars, and stress in prestressing strands are used to investigate flexural behavior of unbonded PC bridge girders.

3.1. Flexural Capacity. Visual observations along with test recording were made during and following loading tests to capture significant changes in unbonded PC T bridge girders. These observations, together with recorded load value and mid-span deflections, were utilized to acquire flexural capacity and failure mode in unbonded PC T bridge girders. The flexural capacity in SP-A, SP-B, and $\mathrm{SP}-\mathrm{C}$, dependent on experiments, is $500 \mathrm{kN} \cdot \mathrm{m}, 506 \mathrm{kN} \cdot \mathrm{m}$, and $468.75 \mathrm{kN} \cdot \mathrm{m}$, respectively. The flexural capacity of SP$\mathrm{C}$ is significantly lower than that of SP-A and B; this is due to the fact that low prestress degree cannot entirely contribute the power of prestressing strands when concrete is completely crushed in large deformation. Therefore, the flexural capacity in unbonded PC bridge girders is influenced by different prestress degree, as shown in Table 3.

3.2. Crack Development and Failure Mode. The initiation and development of cracks in SP-A, SP-B, and SP-C are shown in Figure 4. Herein, the numbers next to crack 


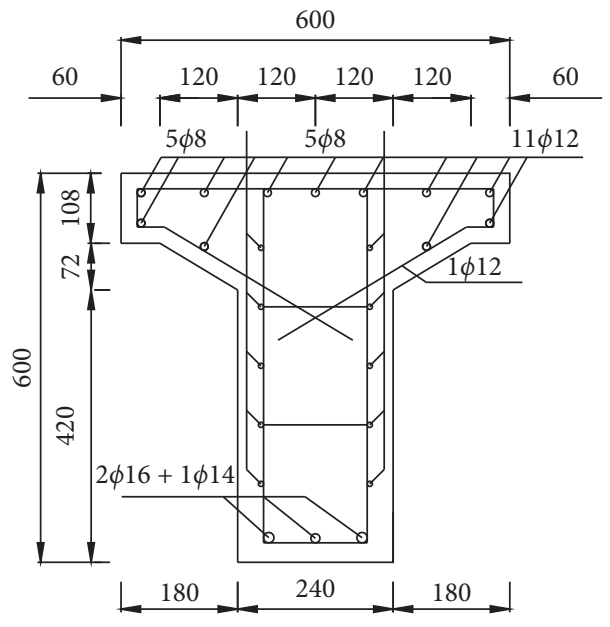

(a)

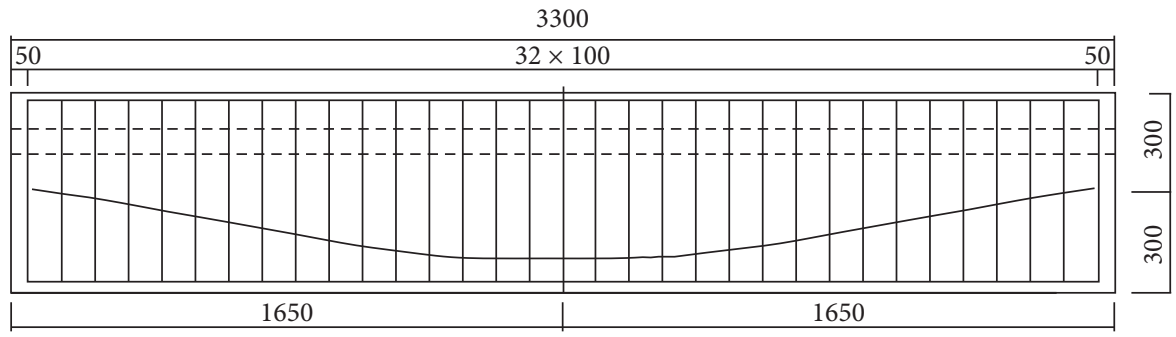

(b)

Figure 1: Layout of specimens. (a) Traverse section. (b) Longitudinal section.

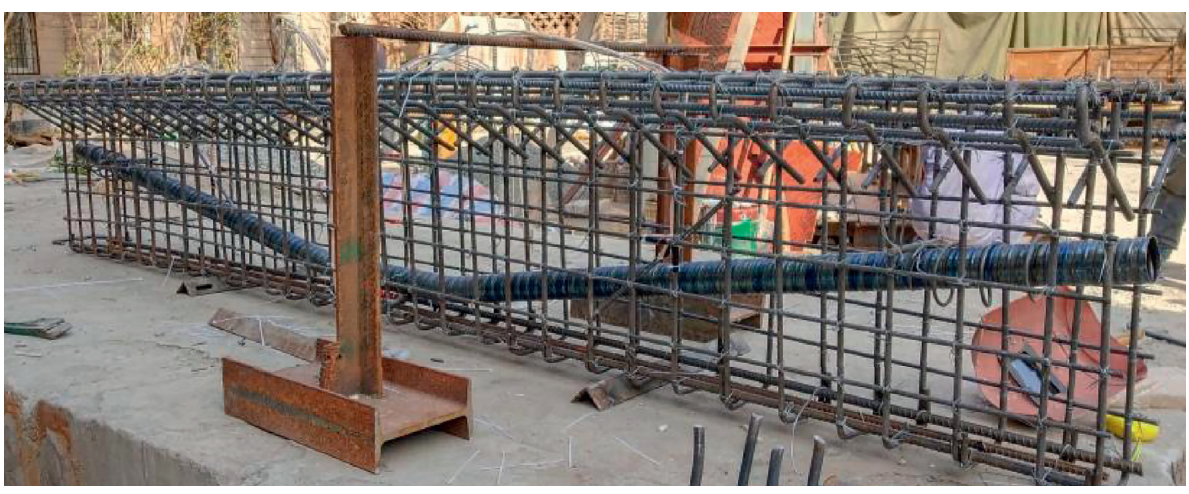

(a)

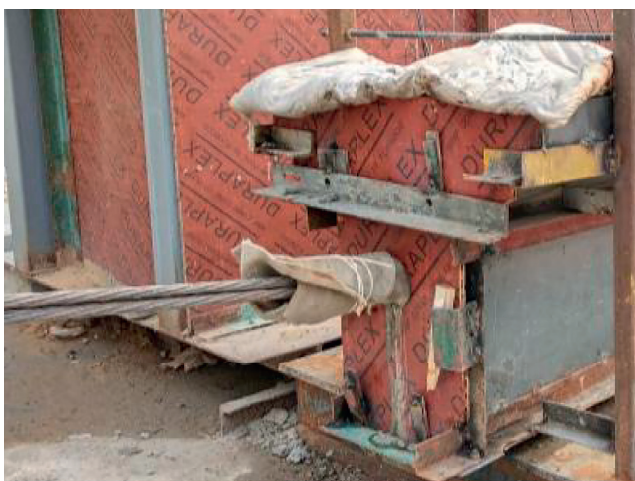

(c)

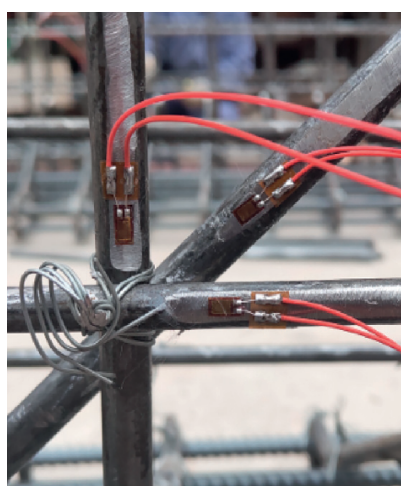

(b)
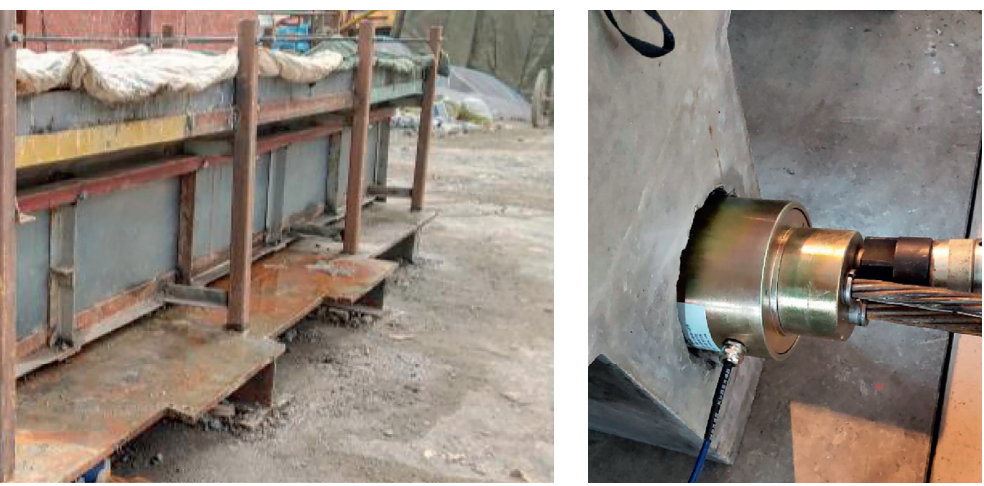

(d)

Figure 2: Fabrication procedure of T bridge girders. (a) Steel frame. (b) Strain gauges. (c) Concrete curing. (d) Pressure sensor. 
Table 1: Properties of concrete, rebar, and prestressing strand.

\begin{tabular}{|c|c|c|c|c|c|}
\hline Symbol & Material & $E_{\mathrm{c}}\left(E_{\mathrm{p}}\right)(\mathrm{MPa})$ & $f_{\mathrm{cu}}(\mathrm{MPa})$ & $f_{\mathrm{y}}(\mathrm{MPa})$ & $f_{\mathrm{u}}\left(f_{\mathrm{p}}\right)(\mathrm{MPa})$ \\
\hline $\mathrm{C} 40$ & Concrete & $3.25 \times 10^{4}$ & 45.41 & - & - \\
\hline A8 & Rebar & $2.10 \times 10^{5}$ & - & 334.34 & 445.48 \\
\hline $\mathrm{B} 12, \mathrm{~B} 14, \mathrm{~B} 16$ & & $2.01 \times 10^{5}$ & - & 421.7 & 589.60 \\
\hline $7 A^{s} 15.2$ & Prestressing strand & $1.95 \times 10^{5}$ & - & 1860 & 1920 \\
\hline
\end{tabular}

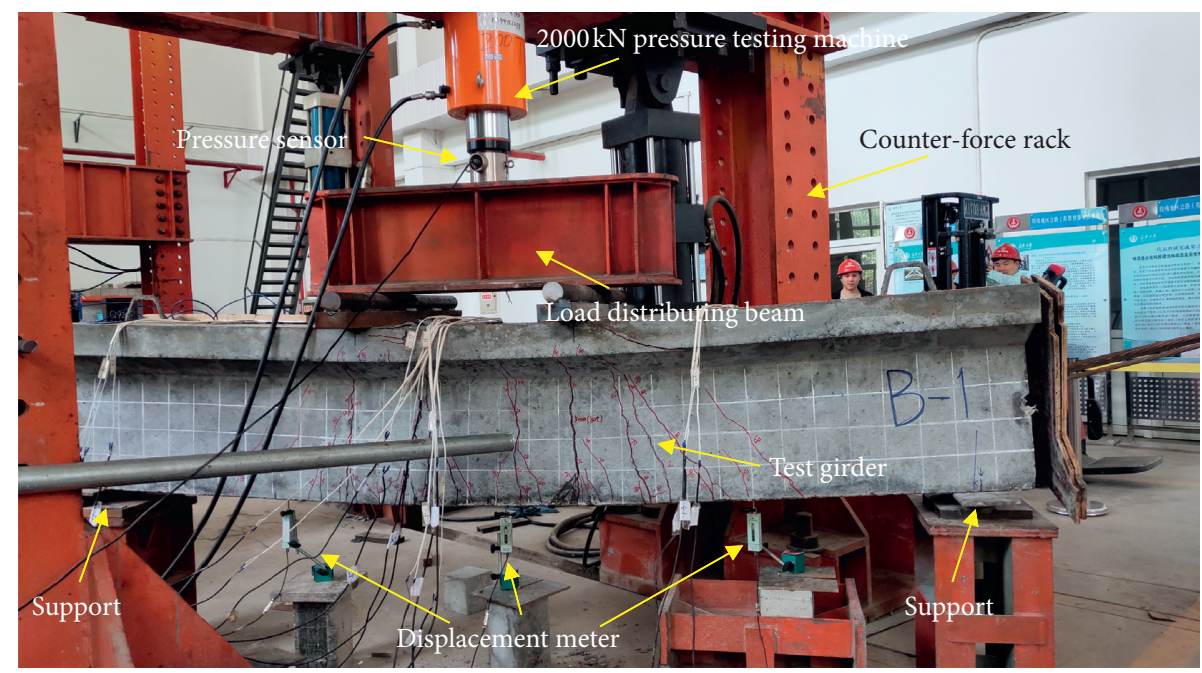

FIgURE 3: Test setup and servo loading system.

represent loading grade. Further, the numbers at the bottom of girder indicate the spacing in main cracks and the distribution zone of all cracks. The initiation and development process of cracks on both sides in the tested girders are highly consistent, which is different from box girders. This is due to the fact that mechanical behavior in two web of box girders may be not symmetric during loading process.

For SP-A, a small clicking sound was emitted when the specimen was loaded to $200 \mathrm{kN}$; simultaneously, two tiny vertical cracks initially appeared within web bottom of the pure bending region. As the load continued to increase, the initial cracks continued to expand and extend. When some oblique cracks began to appear on the web, the two initial tiny cracks had extended towards the loading point. SP-A continued to be loaded to $750 \mathrm{kN}$; concrete between the two loading points on top flange began to crack and then be slightly crushed. In the process of the load increased to $800 \mathrm{kN}$, SP-A gradually failed following concrete crushing and stripping between the loading points, as shown in Figure 4(a). For SP-B, an initial tiny crack occurred under a load of $230 \mathrm{kN}$. Thereafter, some oblique cracks developed between the supports and loading points under a load of about $400 \mathrm{kN}$. When the load reached $800 \mathrm{kN}$, multiple main cracks extended to top flange. Flexural cracks continued to propagate until the failure in the girders occurred, while concrete in top flange crumbled slightly. For SP-C, two initial tiny cracks occurred under loading $150 \mathrm{kN}$. Continued to be loading, the main cracks gradually extended to top flange. When the load reached $750 \mathrm{kN}$, SP-C exhibited
TABLE 2: Design testing parameters in SP-A, SP-B, and SP-C.

\begin{tabular}{lcc}
\hline Specimens & Load spacing $(\mathrm{mm})$ & Pretension $(\mathrm{kN})$ \\
\hline SP-A & 500 & 200 \\
SP-B & 750 & 200 \\
SP-C & 500 & 80 \\
\hline
\end{tabular}

flexural failure, and concrete in top flange was severely striped off.

The crack distribution features in SP-A, SP-B, and SP-C were various under different prestress degree and load conditions. The crack distribution of SP-A was in the range of $1700 \mathrm{~mm}$ at mid-span. Herein, four main cracks were found on the surface with spacing of $210 \mathrm{~mm}, 290 \mathrm{~mm}$, and $150 \mathrm{~mm}$, respectively. The distribution range of fracture in SP-B was wide that could reach $1900 \mathrm{~mm}$, and five main cracks were generated uniformly in the range of $190 \mathrm{~mm}$ to $250 \mathrm{~mm}$. Due to the lower prestress degree in SP-C, the main cracks develop rapidly and the damage was concentrated in a slightly small range with $1600 \mathrm{~mm}$.

Figure 5 describes the development process of the main crack width in specimens, where the normalized load capacity can be defined as a ratio of load applied to ultimate flexural capacity. Cracks rarely occur on specimens in the elastic stage, while the critical point of cracking is between 0.20 and 0.28 in specimens. Then, as the load increases, the crack width increases to $0.3 \mathrm{~mm}$. This crack width has reached limit state as per provisions from AASHTO [12]. The corresponding normalized load capacity in SP-A and 
TABle 3: Summary of test results.

\begin{tabular}{lcccccc}
\hline Specimen & $\begin{array}{c}\text { Prestress degree } \\
(\%)\end{array}$ & $\begin{array}{c}\text { Cracking load } \\
(\mathrm{kN})\end{array}$ & $\begin{array}{c}\text { Maximum load } \\
(\mathrm{kN})\end{array}$ & $\begin{array}{c}\text { Flexural capacity } \\
(\mathrm{kN} \cdot \mathrm{m})\end{array}$ & $\begin{array}{c}\text { Maximum mid-span } \\
\text { deflection }(\mathrm{mm})\end{array}$ & $\begin{array}{c}\text { Residual deflection } \\
(\mathrm{mm})\end{array}$ \\
\hline SP-A & 25.6 & 200 & 800 & 500 & 62 & 46 \\
SP-B & 25.6 & 230 & 880 & 506 & 58 & 43 \\
SP-C & 10.3 & 150 & 750 & 468.75 & 64 & 52 \\
\hline
\end{tabular}

SP-B is between 0.50 and 0.55 , which meets the requirement of ultimate state under normal serviceability [13]. As the load continues to increase, the development of main crack width in SP-B is slower as compared to SP-A and SPC. Therefore, the cracks development of specimens indicates that high prestress degree and large load spacing can delay the propagation of main cracks in flexural zone of the girder.

3.3. Load-Deflection Curves. Figure 6 shows the load-deflection curves of SP-A, SP-B, and SP-C at the mid-span, which can be divided into four stages, namely, the elastic stage, the elastic-plastic stage, the ductility stage, and the unloading stage.

For SP-A, the mid-span deflection exhibits a linear relation with increasing loads in the elastic stage. SP-A enters elastic-plastic stage when the load is applied up to $200 \mathrm{kN}$ ( $25 \%$ of the maximum load). The stiffness presents an obvious variety after concrete cracking, as shown in Figure 6(a). The maximum deflection can reach $10 \mathrm{~mm}(\mathrm{~L} / 300)$ in this stage. In the ductility stage, mid-span deflection increases rapidly due to degradation of flexural stiffness. Finally, when the load reaches $800 \mathrm{kN}$, the mid-span deflection is $62 \mathrm{~mm}$ (more than $\mathrm{L} / 50$ ). Then, $\mathrm{SP}-\mathrm{A}$ is regarded as failure, which exhibits ductile failure [14]. After unloading, the residual deflection is $46 \mathrm{~mm}$, presenting a good ductility and deformation recovery capability.

The load-deflection curves of SP-B and SP-C are similar to that of SP-A, as shown in Figures 6(b) 6(c). In the beginning, the load-deflection curves in SP-B and SP-C present linear states before cracking loads of $250 \mathrm{kN}$ and $150 \mathrm{kN}$ ( $28 \%$ and $20 \%$ of the maximum load), respectively. When the load exceeds $450 \mathrm{kN}$ for SP-B and $350 \mathrm{kN}$ for SP-C, SP-B and SP-C enter the ductility stage. Subsequently, the maximum mid-span deflection is $58 \mathrm{~mm}$ in SP-B and $64 \mathrm{~mm}$ in SP-C. After unloading, the residual deflection in SP-B and SP-C is $43 \mathrm{~mm}$ and $52 \mathrm{~mm}$, respectively.

The load-deflection curves in SP-A, SP-B, and SP-C, with similar trend at the initial loading stage, present an obviously different tendency towards the final stage of loading, as shown in Figure 6(d). These curves, indicating high prestress degree within a specific range, can effectively improve the flexural rigidity after concrete cracking in unbonded PC T bridge girders.

3.4. Strain in Longitudinal Rebars. Taking SP-A as an example, strain in longitudinal rebars varying with loads is shown in Figure 7. A-1 is located in top flange, and also A-2, A-3, and A-4 are located in web top, web middle, and web bottom, respectively.
It can be seen from Figure 7 that strains in longitudinal rebars, except A-4, are small when the applied loading is less than cracking loads. As the load continues to increase, the longitudinal rebars in top flange present negative strain due to compression. When the load increases to $400 \mathrm{kN}$, the strain of rebars in A-4 is $2040 \mu \varepsilon$. When the load is up to $800 \mathrm{kN}$, the rebar in A-1 reaches yield and the negative strain is $2460 \mu \varepsilon$, with concrete being severely crushed.

3.5. Stress in Prestressing Strands. The stress in unbonded prestressing strands is assumed to be uniformly distributed along the girder and can reflect the flexural behavior of unbonded PC T bridge girders. Herein, the micro-strain in pressure sensor can be measured by instrument, and the stress in prestressing strands can be calculated by

$$
\left\{\begin{array}{l}
P=\Delta \varepsilon \times k, \\
\sigma=P / A_{p},
\end{array}\right.
$$

where $P$ is the tension in prestressing strands, $\Delta \varepsilon$ is the micro-strain in pressure sensor, $k$ is the calibration parameter of pressure sensor with $1.2698,1.2559$, and 1.2903 in SP-A, SP-B, and SP-C, respectively, $A_{\mathrm{p}}$ is the area of prestressing strands, and $\sigma$ is the stress in prestressing strands.

The load-stress curves in prestressing strands of SP-A, SP-B, and SP-C are shown in Figure 8. The change of stress in prestressing strands is tiny at the early loading stage with small deflection of bridge girders simultaneously. After the yield point, stress in prestressing strands increases rapidly due to the large bending deflection of bridge girders; herein the change of stress in SP-C is significant. The stress in prestressing strands of SP-A, SP-B, and SP-C is $1414.4 \mathrm{MPa}$, 1396.4 MPa, and 1658.9 MPa, respectively. This difference is mainly due to the fact that SP-C presents the lowest prestress degree and the largest mid-span deflection. Therefore, the stress in prestressing strands is mainly related to the bending deflection of bridge girders.

After tests, prestressing strands, difficultly pulled out from the tube, were found that some strands had been fractured, as shown in Figure 9. The fracture ratios of strands in SP-A, SP-B, and SP-C are 57.1\%, 42.8\%, and 9.5\%, respectively. Wherein, considering the initial stress, the ultimate tensile stress of prestressing strands in SP-A, SP-B, and SP-C is $1890.4 \mathrm{MPa}$, $1872.6 \mathrm{MPa}$, and $1849.3 \mathrm{MPa}$, respectively, which is lower than the tested tensile strength of $1920 \mathrm{MPa}$. This is due to the fact that prestressing strands are not completely perpendicular to anchorage port and also the tensioning of three strands is uneven in one specimen. Therefore, during the prefabrication of unbonded PC bridge girders, multiple unbonded prestressing strands should be 


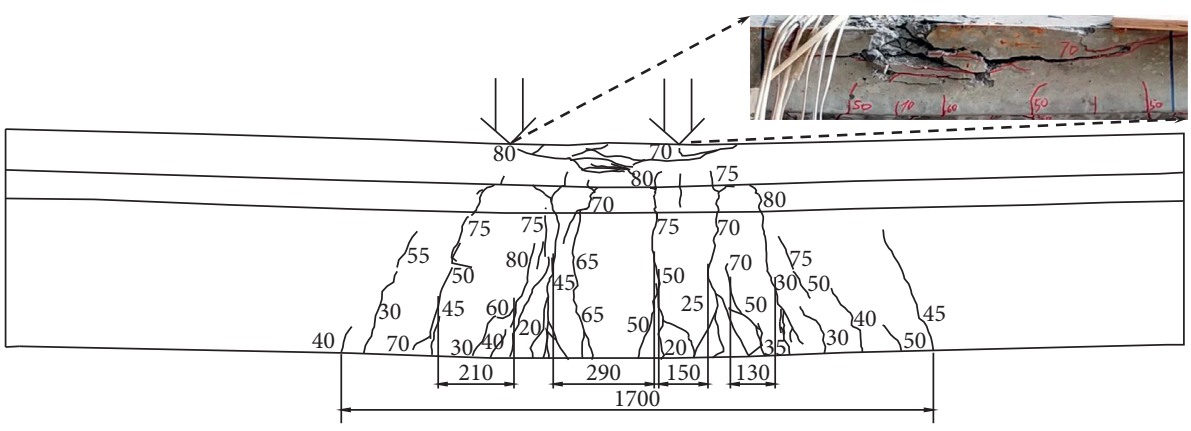

(a)

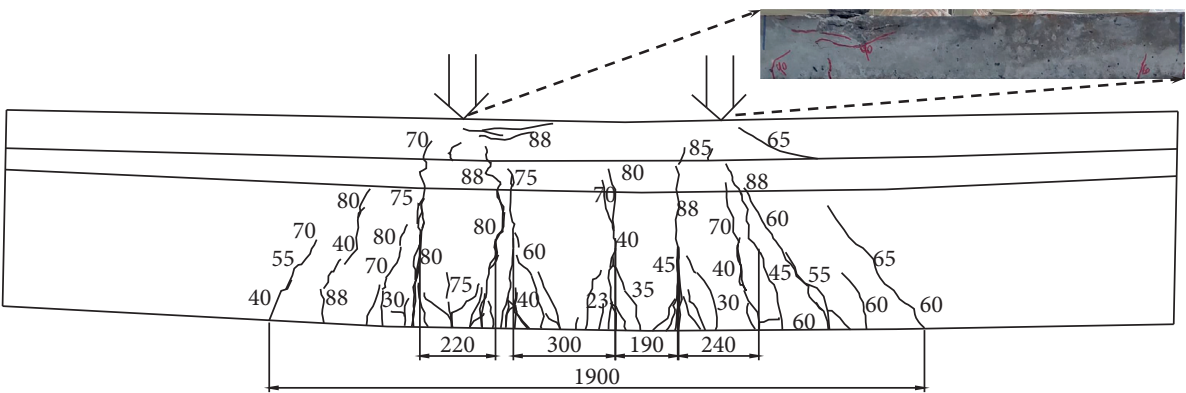

(b)

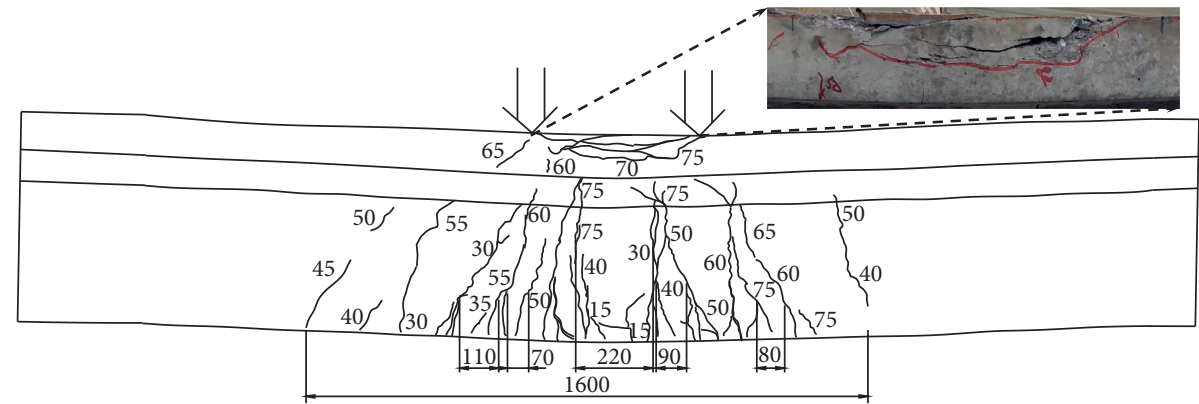

(c)

FIGURE 4: Crack pattern in SP-A, SP-B, and SP-C ( $\times 10 \mathrm{kN})$. (a) SP-A. (b) SP-B. (c) SP-C.

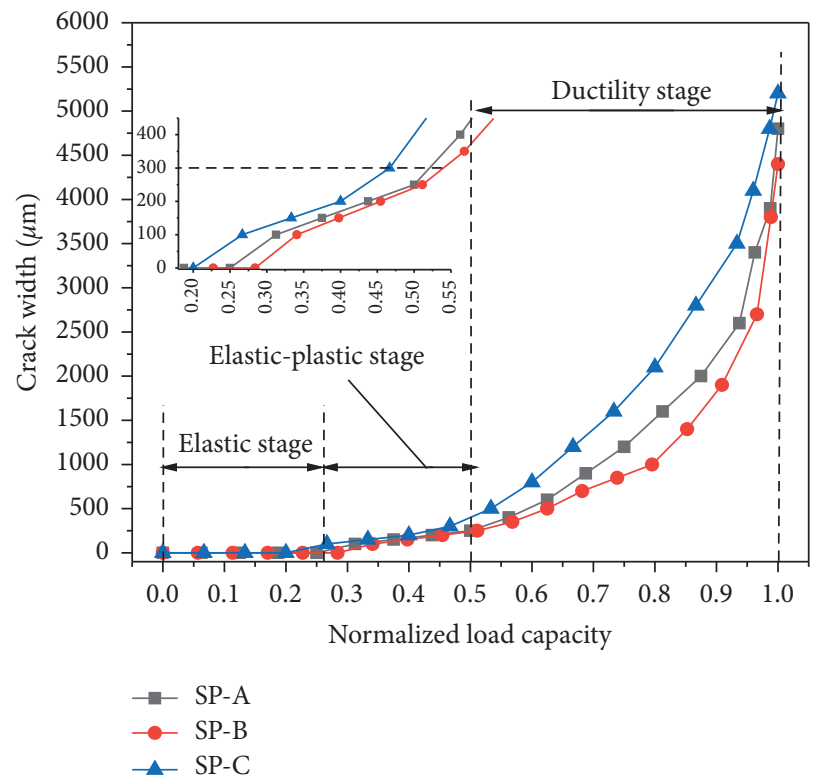

FIgURE 5: Crack width and normalized loading capacity. 


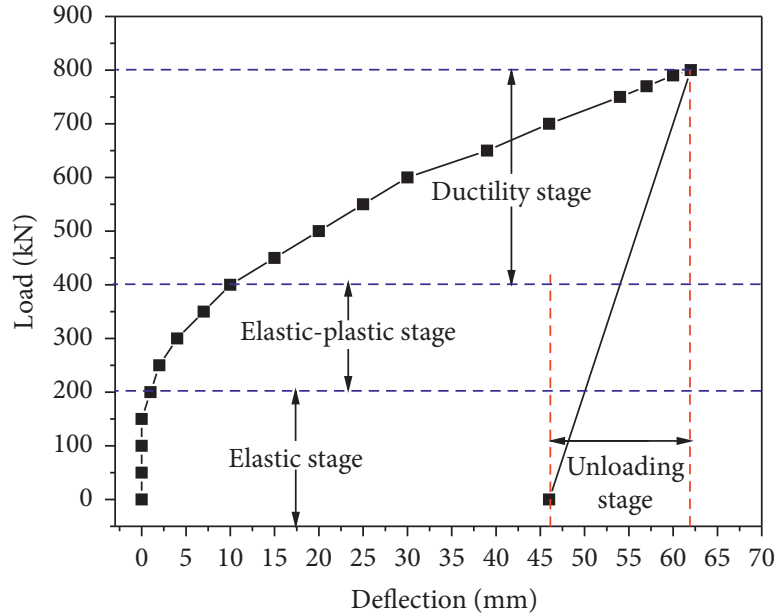

(a)

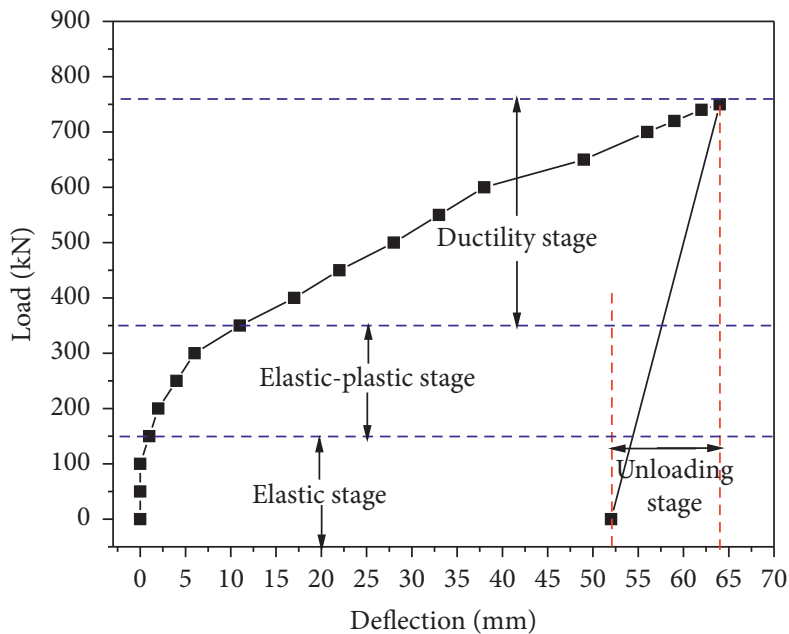

(c)

Figure 6: Load-deflection curves. (a) SP-A. (b) SP-B. (c) SP-C. (d) SP-A, SP-B, and SP-C.

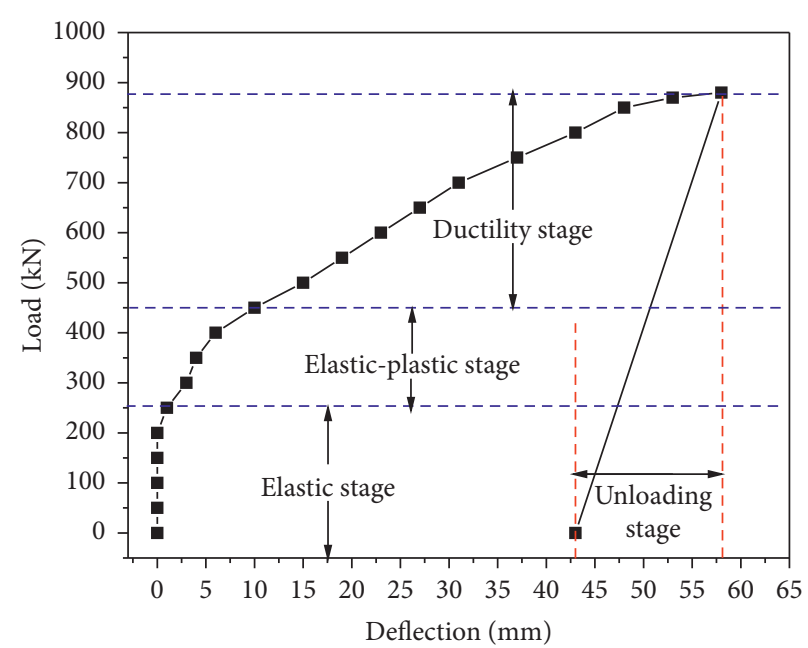

(b)

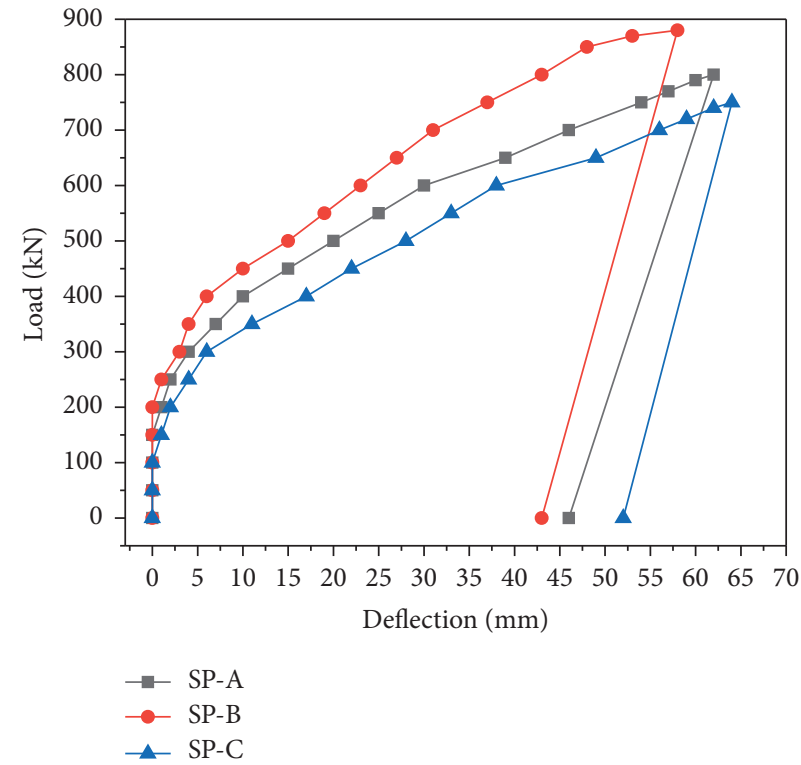

(d) simultaneously tensioned and perpendicular to anchorage port, preventing the fracture of prestressing strands.

\section{Numerical Studies}

A three-dimensional finite element (FE) model, taking into account material and geometric nonlinearity, is established using ANSYS to further investigate the flexural behavior of unbonded PC T bridge girders.

4.1. Finite Element Model. As shown in Figure 10, concrete is modeled with SOLID65; rebars and prestressing stands are modeled with LINK8. Cushions and supports are modeled with thick rigid units of SOLID185. The bond condition between rebars and concrete is established by constraint equation. Further, the constraint of prestressing strands in the $z$ direction is released, except at the both ends, so as to consider the unbonded action. Same nodes are utilized to simulate the perfectly bonded behavior between support and bottom surface of bridge girder, and this method is also applicable to cushion and top surface of bridge girder. Unbonded PC T bridge girders are simulated under the same conditions as the experimental tests.

4.2. Analysis Details. The numerical studies in concrete are realized through MELAS model. Herein, the stress-strain relation is provided dependent on a traditional Hognestad model [15]. The numerical studies in rebars and prestressing strands are performed using BKIN model, wherein the stress-strain relation of them is applied utilizing an ideal elastic-plastic model [16].

The above FE model is adopted to simulate the flexural behavior of unbonded PC T bridge girders. The load, applied on the cushion, is utilized to simulate uniform loads. An 


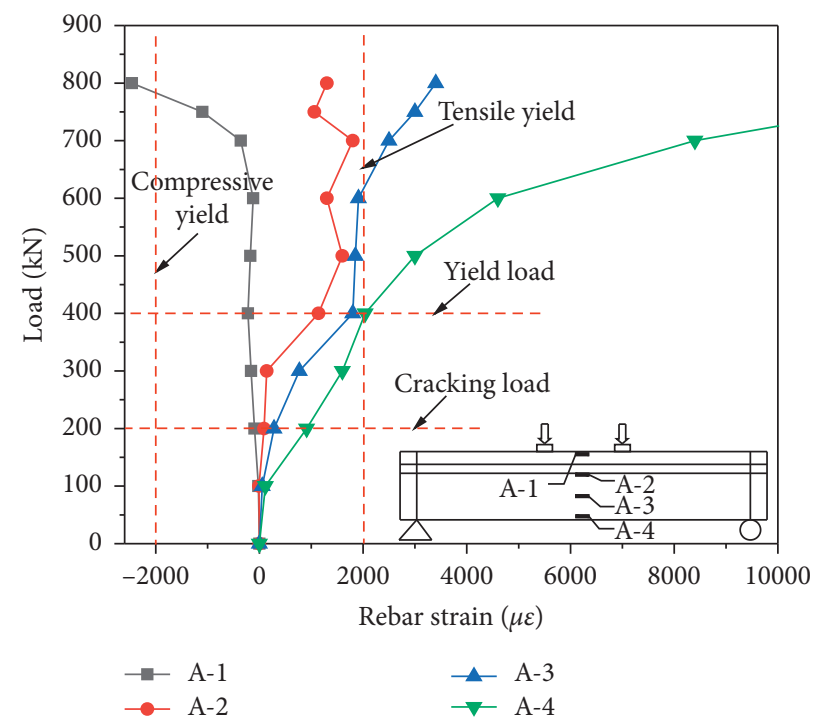

FIgURE 7: Load-strain curves in longitudinal rebars.

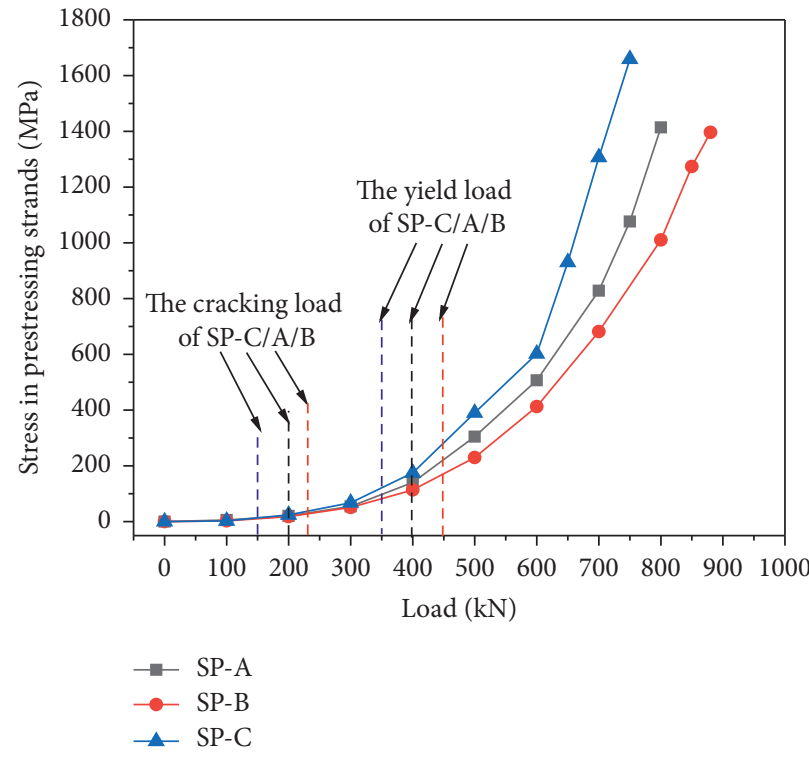

Figure 8: Load-stress curves in prestressing strands.

automatic time step together with load substeps in range of 50-120 is employed to perform the nonlinear analysis. The convergence norm of forces, 0.05 , is used to attain an effective solution.

\section{Model Validation}

The predictions of flexural behavior from FE models are compared with the results generated from flexural experiments on specimens to verify the effectiveness of numerical analysis. Figure 11 shows the comparison of load-deflection curve generated from tests and numerical analysis, wherein the load-deflection curves of tests are in good agreement with that of numerical analysis, and the error between the test results and FE model is less than $1 \%$. In the later ductility stage, the slope of load-deflection curves obtained by numerical analysis is slightly larger than that obtained by experimental. This is mainly due to the fact that the prefabrication of model girder is challenging to meet the ideal state. As shown in Figure 12, the distribution, development, and location of cracks and the crushed state of concrete in compression zone generated 


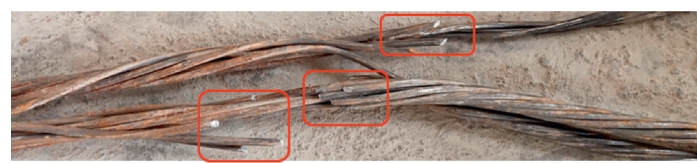

(a)

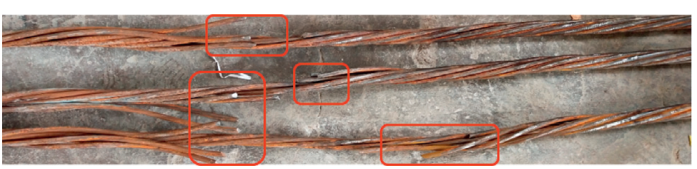

(b)

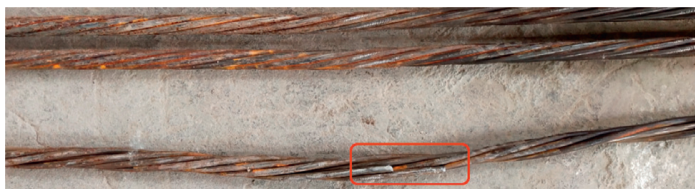

(c)

Figure 9: Fracture in prestressing strands. (a) SP-A. (b) SP-B. (c) SP-C.

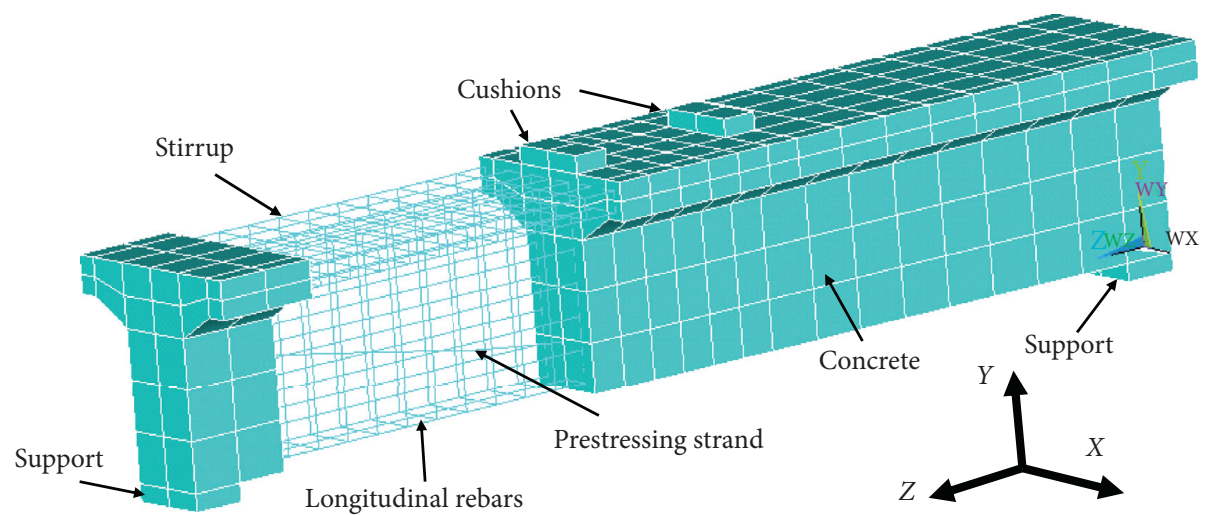

FIgURE 10: FE model of unbonded PC T bridge girders.

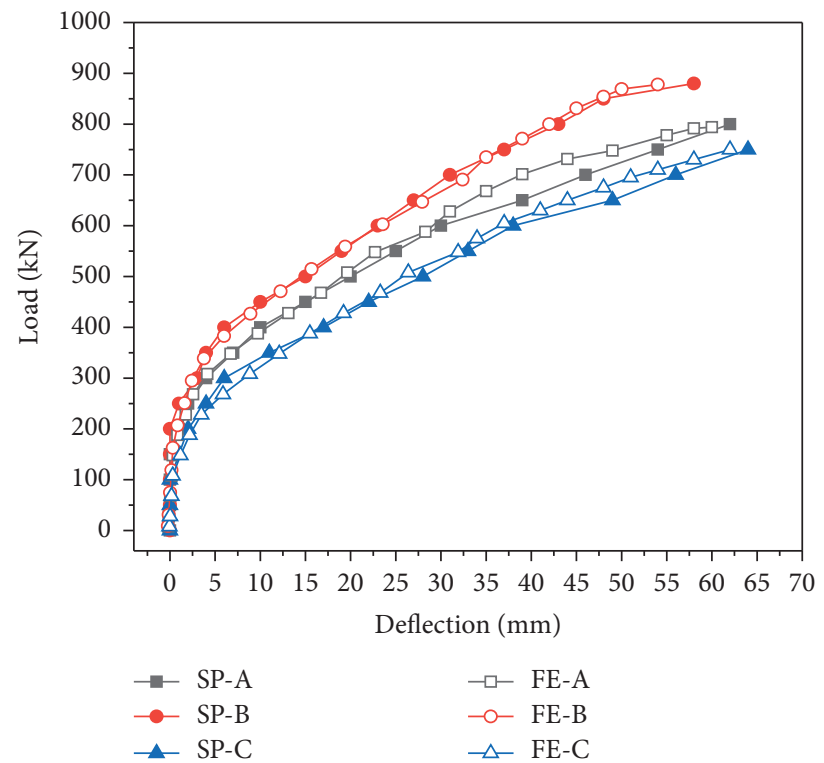

Figure 11: Comparison of load-deflection curves from tests and numerical analysis. 


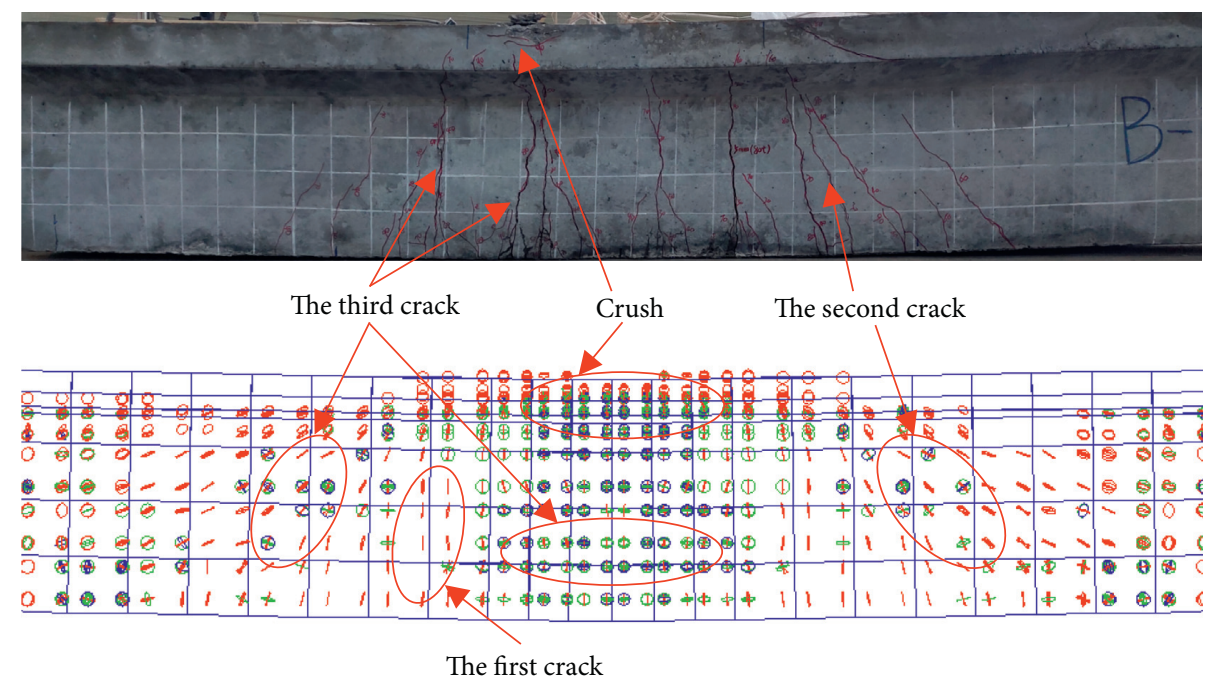

FIGURE 12: Comparison of concrete cracks from tests and numerical analysis.

from tests are in good agreement with the numerical analysis results. Therefore, the developed FE models can accurately simulate the flexural behavior of unbonded PC $\mathrm{T}$ bridge girders.

\section{Parametric Studies}

Parametric studies were conducted using the validated FE models to investigate the effects of concrete strength, reinforcement ratio, prestress degree, and bending angle on flexural behavior of unbonded PC T bridge girders, as shown in Figure 13.

Concrete strength has little influence on the flexural performance of unbounded PC bridge girders in the elastic stage and elastic-plastic stage (see Figure 13(a)). However, improving concrete strength can slightly enhance the ultimate flexural capacity of unbonded PC T bridge girders in the ductility stage. When the concrete strength increases from $\mathrm{C} 40$ to $\mathrm{C} 60$, the ultimate flexural capacity increases by $4.9 \%$. This is mainly due to the fact that compressive zone concrete has a certain contribution to the flexural performance.

The effect of different reinforcement ratios on flexural behavior of unbounded PC bridge girders is studied by changing the area of bottom tensile rebars, as shown in Figure 13(b). It can be found that increasing reinforcement ratio can significantly improve the ultimate flexural capacity of bridge girders. Compared with FE-A, the ultimate flexural capacity of the other two FE models is increased by $8 \%$ and $12 \%$, respectively.

Increasing prestress degree cannot significantly improve the ultimate flexural capacity of unbounded PC bridge girders. However, it can effectively enhance the flexural rigidity, thus delaying the cracks' opening. Therefore, the flexural behavior of unbonded PC T bridge girders can be improved by increasing prestress degree, as can be seen in Figure 13(c).

The load-deflection curves in unbonded PC $\mathrm{T}$ bridge girders with prestressing strands bending angle of $0^{\circ}, 4^{\circ}, 9^{\circ}$, and $12^{\circ}$ are utilized to study its effect on flexural behavior of unbounded PC bridge girders, as shown in Figure 13(d). The stress loss in unbonded prestressing strands resulted from friction is slight, so that the load-deflection curves with bending angle of $0^{\circ}, 4^{\circ}$, and $9^{\circ}$ are basically coincident. However, the load-deflection curve with bending angle of $12^{\circ}$ appears slightly different. The excessive bending angle cannot be applicable to prestressing strands in unbonded PC $\mathrm{T}$ bridge girders.

\section{Practical and Design Implications}

Unbonded PC T bridge girders illustrated herein are utilized to apply in construction of medium- and small-span bridges and rapid replacement of hollow-slab bridge girders with serious diseases. When combined with the fact, controlling the bending angle of prestressing strands less than $12^{\circ}$ and increasing prestress degree appropriately without cracking in top flange can improve the flexural performance of unbonded PC T bridge girders. For practical design of unbounded PC T bridge girders, the flexural behavior of bridge girders can be effectively improved with highstrength concrete and high-ratio rebars in bottom flange simultaneously. Further, the prestressing strands are suggested to be simultaneously tensioned in the prefabrication process of unbonded PC T bridge girders to ensure the same stress in each strand [17-19]. 


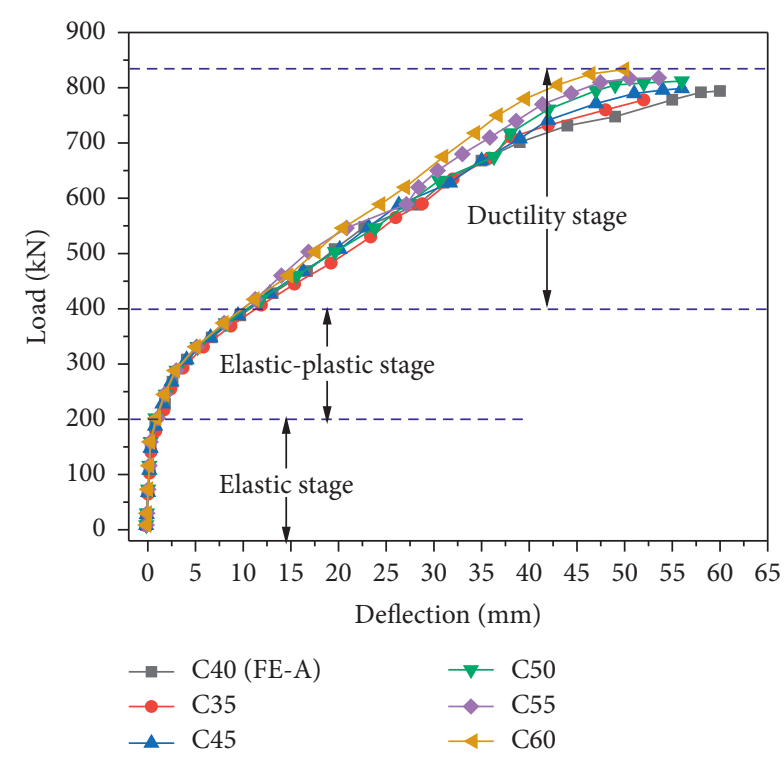

(a)

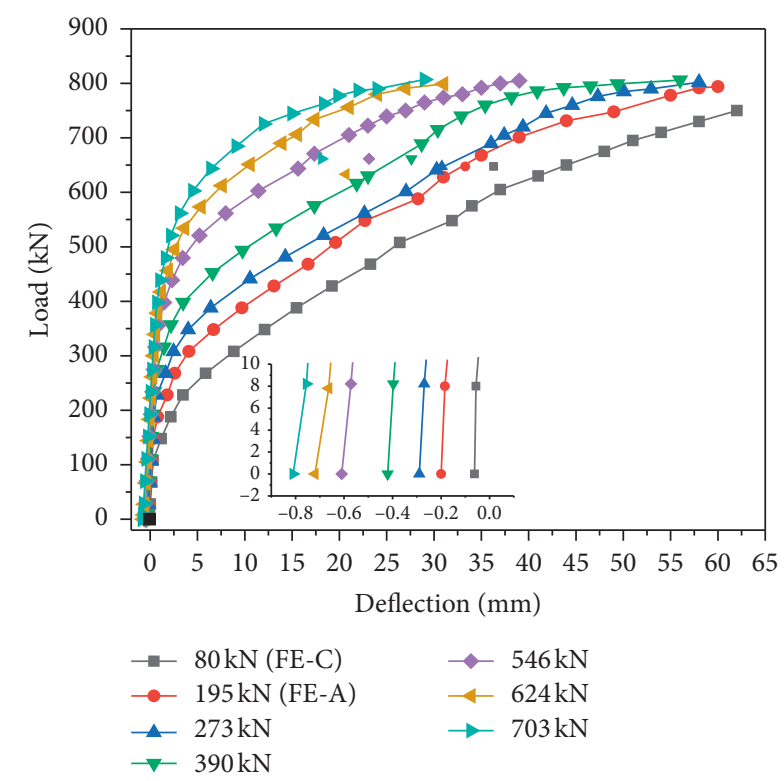

(c)

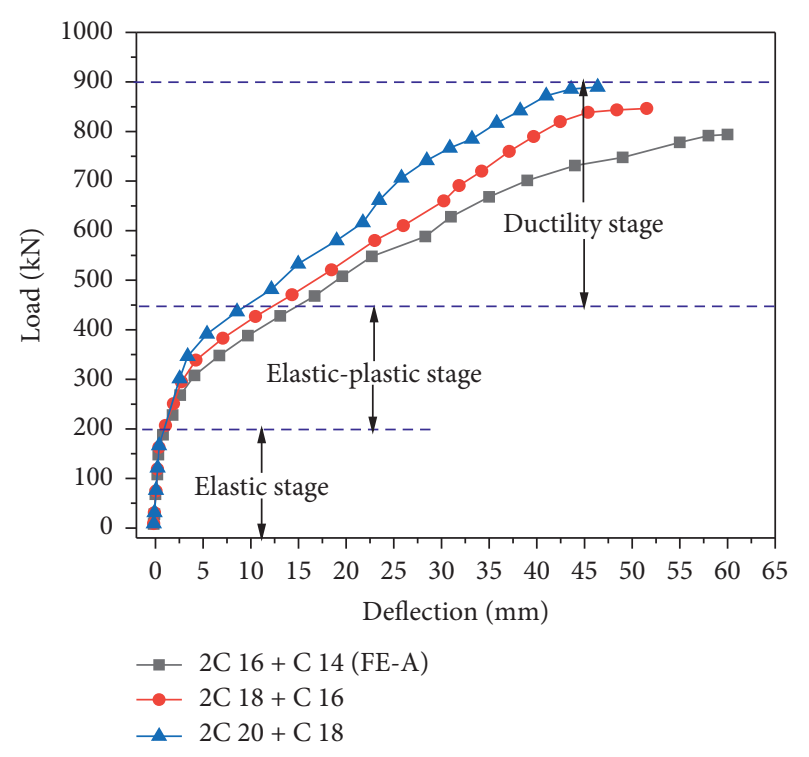

(b)

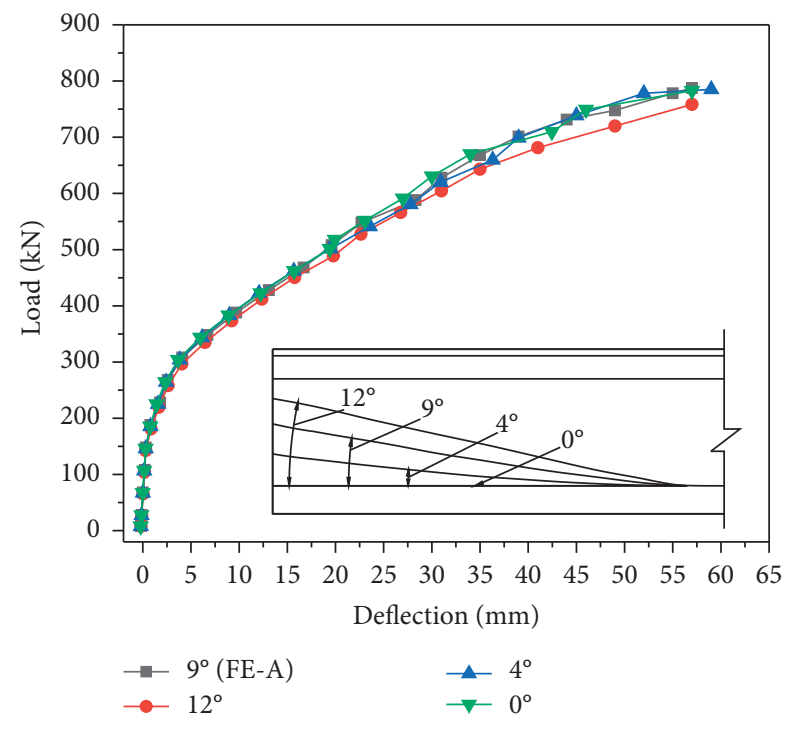

(d)

Figure 13: Load-deflection curves with single parameter. (a) Concrete strength. (b) Reinforcement ratio. (c) Prestress degree. (d) Bending angle.

\section{Conclusion}

Based on the information presented in this paper, the following conclusions can be drawn:

(1) The flexural destruction behavior of unbonded PC T bridge girders experiences elastic, elastic-plastic, and ductility stages, similar to that of PC T bridge girders. Unbonded PC $\mathrm{T}$ bridge girders present superior ductility and deformation-recovery ability after unloading.

(2) The prestress degree has a significant influence on the destruction process in unbonded PC $\mathrm{T}$ bridge girders. The main cracks in unbonded PC $\mathrm{T}$ bridge girders have obvious characteristics with concentrated distribution, small number, and large width when deceasing prestress degree.

(3) Increasing the load spacing can significantly improve the flexural capacity and also slightly enlarge the distribution range and number of cracks, while the width of cracks can be reduced.

(4) Stress in prestressing strands under anchor increases rapidly after concrete presents obvious cracks. The unsynchronized tensioning of prestressed strands can easily lead to partially fractured in strands.

(5) Merely increasing concrete strength has a slight influence on the flexural rigidity and flexural 
capacity of unbonded PC girders. The ratio of longitudinal rebars at the bottom has a significant influence on the flexural behavior in the elastic and elastic-plastic stage.

(6) The flexural behavior of unbonded PC T bridge girders can be affected when the bending angle of prestressing strands reaches a certain level.

\section{Data Availability}

The data used to support the findings of this study are included within the article.

\section{Conflicts of Interest}

The authors declare that there are no conflicts of interest regarding the publication of this paper.

\section{Acknowledgments}

The authors acknowledge the support from Communication Science and Technology Project in Shaanxi Province (Grant nos. 20-45K), Communication Science and Technology Project in Ningxia Province (Grant no. 201700166), and Natural Science Foundation (Grant no. 51878057).

\section{References}

[1] F. Peng and W. Xue, "Calculating method for ultimate tendon stress in internally unbonded prestressed concrete members," ACI Structural Journal, vol. 116, no. 5, 2019.

[2] L. S. Moreira, J. B. M. Sousa, and E. Parente, "Nonlinear finite element simulation of unbonded prestressed concrete beams," Engineering Structures, vol. 170, pp. 167-177, 2018.

[3] P. M. Páez and B. Sensale, "Improved prediction of long-term prestress loss in unbonded prestressed concrete members," Engineering Structures, vol. 174, pp. 111-125, 2018.

[4] P. M. Lazzari, A. C. Filho, F. P. S. L. Gastal et al., "Automation of the evaluation of bonded and unbonded prestressed concrete beams, according to Brazilian and French code specifications," Revista Ibracon de Estruturas E Materiais, vol. 6, no. 1, 2018.

[5] S. Li, Y. Zhang, and W. Chen, "Bending performance of unbonded prestressed basalt fiber recycled concrete beams," Engineering Structures, vol. 221, Article ID 110937, 2020.

[6] M. S. Kim, Y. H. Lee, and L. Evangelista, "Flexural behavior of posttensioned concrete beams with unbonded high-strength strands," Advances in Materials Science and Engineering, vol. 2020, Article ID 5317456, 12 pages, 2020.

[7] ACI Committee 318, Building Code Requirements for Reinforced Concrete and Commentary (ACI 318-19), American Concrete Institute, Farmington Hills, MI, USA, 2019.

[8] American Association of State and Highway Transportation Officials, AASHTO LRFD Bridge Design Specifications, American Association of State and Highway Transportation Officials, Washington, DC, USA, 2010.

[9] M. Bonopera, K. C. Chang, C. C. Chen et al., "Experimental study on the fundamental frequency of prestressed concrete bridge beams with parabolic unbonded tendons," Journal of Sound and Vibration, vol. 455, pp. 150-160, 2019.

[10] P. Six, R. Tawadrous, P. Syndergaard et al., "Flexural behavior of three span continuous unbonded post-tensioned members with variable bonded reinforcement," Engineering Structures, vol. 200, 2019.

[11] T. J. Lou and Y. Q. Xiang, "Effects of ordinary tension reinforcement on the response of beams with unbonded tendons," Advances in Structural Engineering, vol. 10, no. 1, 2009.

[12] AASHTO, LRFD Bridge Design Specifications (LRFD-8), American Association of State Highway and Transportation of Officials, Washington DC, USA, 2017.

[13] M. A. Rashid and M. A. Mansur, "Reinforced high-strength concrete beams in flexure," ACI Structural Journal, vol. 102, no. 3, 2005.

[14] Y. Chen, J. Dong, Z. Tong et al., "Flexural behavior of composite box girders with corrugated steel webs and trusses," Engineering Structures, vol. 209, Article ID 110275, 2020.

[15] E. Hognestad, N. W. Hanson, and D. McHenry, "Concrete stress distribution in ultimate strength design," Journal Proceeding, vol. 52, no. 12, 1955.

[16] X. Wang, Ansys Engineering Structure Numerical Analysis, China Communications Press, Beijing, China, 2007. 